\title{
Sustainable Optimization for thermal comfort and building energy efficiency in Cairo
}

\author{
Sahar Mohamed Abd El-Rahman ${ }^{\text {a }}$, Sobhy Ibrahim Esmail ${ }^{\mathrm{b}}$, Husam Bakr Khalil ${ }^{\mathrm{c}}$, Zeinab \\ El-Razaz ${ }^{\mathrm{d}}$ \\ ${ }^{a}$ Ph.D. Student, Architecture Department, Faculty of Engineering Mattaria, Helwan University. Teaching Assistant at Modern \\ Academy. \\ ${ }^{\mathrm{b}}$ Ph.D. Student, Teaching Assistant, Architecture Department, Faculty of Engineering Mattaria, Helwan University. \\ ${ }^{c}$ Professor of Architecture, Architecture Department, Faculty of Engineering, The British University in Egypt (BUE). \\ ${ }^{d}$ Professor of Architecture, Architecture Department, Faculty of Engineering Mattaria, Helwan University .
}

\begin{abstract}
Globally, a significant proportion of the building energy is consumed for achieving the required thermal and optical comfort. The building form and the other associated factors heavily affect the indoor thermal comfort and the lighting energy of any air-conditioned or naturally ventilated building. The most important parameters affecting the thermal comfort and lighting energy requirement of the indoor environment are the building shape, orientation and the window to wall ratio (WWR) of the building. These parameters are interrelated and a proper combination is required to achieve the optimal thermal comfort and energy efficiency.
\end{abstract}

Keywords: Optimization - thermal and optical comfort - Energy efficiency Building energy simulation.

The aim of this study is to determine the thermal performance of office buildings with Optimizing the shape, orientation and the window to wall ratio (WWR) of the building.

\section{Introduction}

The development in computer technology have improved capacity of handling complex simulation models have enabled more accurate calculations of the energy performance. This can hopefully be used as a design tool already at an early stage, making it possible to design an optimal envelope Building performance simulations are an integral part of the design process for energy efficient and high-performance buildings, since they help in investigating design options and assess the environmental and energy impacts of design decisions. Energy efficient buildings aim to reduce the overall energy consumption necessary for their operation. Highperformance buildings are designed to improve the overall building performance, besides energy usage, such as improving occupants' thermal, visual and acoustic comfort.

\section{Choose simulation programs to evaluate proposal models}

\subsection{Tools selection criteria}

The simulation community at large is thinking about and discussing at least five major challenges. As shown in Figure 02 they are namely, the (1) Usability and Information Management (UIM) of interfaces, (2) Integration of Intelligent design Knowledge-Base (IIKB), (3) Accuracy of tools and Ability to simulate Detailed and 
Complex and building Components (AADCC), (4) Interoperability of Building Modelling (IBM) and the (5) Integration with Building Design Process (IBDP) [1].

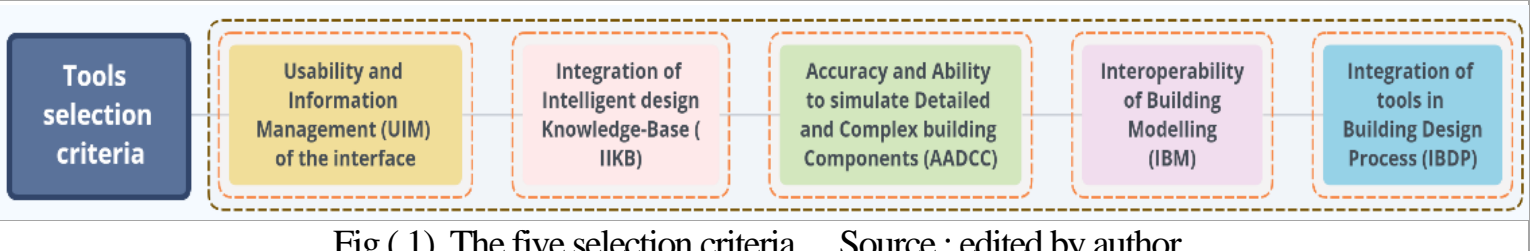

\subsection{Comparison of the existing environmental analysis tools for Rhino/Grasshopper}

There are currently five environmental analysis tools, for Rhino/Grasshopper, available to the public .Table 1 compares the existing environmental analysis tools for Rhino/Grasshopper based on the analysis types that they provide during the different stages of an environmental design process. As it is shown in Table 1, none of the tools provide the full spectrum of the environmental studies, and there is almost no support for weather data analysis. [2]

Table (1). Comparison of the existing environmental analysis tools for Rhino/Grasshopper.

\begin{tabular}{|c|c|c|c||c||c|c|}
\hline \multicolumn{2}{|c|}{ Processes } & \multicolumn{5}{c|}{ Analysis Tools } \\
\cline { 3 - 7 } & Heliotrope & Geco & Ladybug & Gerilla & Diva \\
\hline $\begin{array}{c}\text { Climate } \\
\text { Analysis }\end{array}$ & Analysis & & & $\checkmark$ & & \\
\hline \multicolumn{2}{|c|}{ Massing Studization } & $\checkmark * *$ & & $\checkmark$ & & \\
\hline \multicolumn{2}{|c|}{ Orientation Study } & & $\checkmark$ & $\checkmark$ & & $\checkmark$ \\
\hline \multicolumn{2}{|c|}{ Energy Modeling } & & $\checkmark$ & $\checkmark$ & & $\checkmark$ \\
\hline * Limited to one thermal zone & & & $\checkmark$ & $\checkmark$ & $\checkmark *$ \\
\hline
\end{tabular}

\subsection{Define the chosen tools for thermal simulation and Optimization}

\section{- Grasshopper}

In recent years, the design professions have begun experimenting with parametric design tools such as Grasshopper which was developed by David Rutten at Robert McNeel\& Associates in 2007 as a parametric modelling plug-in for Rhinoceros 3D modeling software . [3] Grasshopper is a graphical algorithm editor that allows designers with no formal scripting experience to quickly generate parametric forms from the simple to the awe-inspiring [4] as there are components within Grasshopper that allow custom scripts to be written in VB.NET. [5]

\section{- Ladybug and Honeybee}

Ladybug and Honeybee are efforts to support the full range of environmental analysis in a single parametric platform. Its create interactive $2 \mathrm{D}$ and $3 \mathrm{D}$ graphics for weather data visualization to support the decision making process during the initial stages of design, and the components evaluate initial design options for implications to the design from radiation and sunlight-hours analyses results. Its also provide energy and daylighting modeling by using validated simulation engines such as EnergyPlus (US Department of Energy), Radiance [6], and Daysim [7]. 


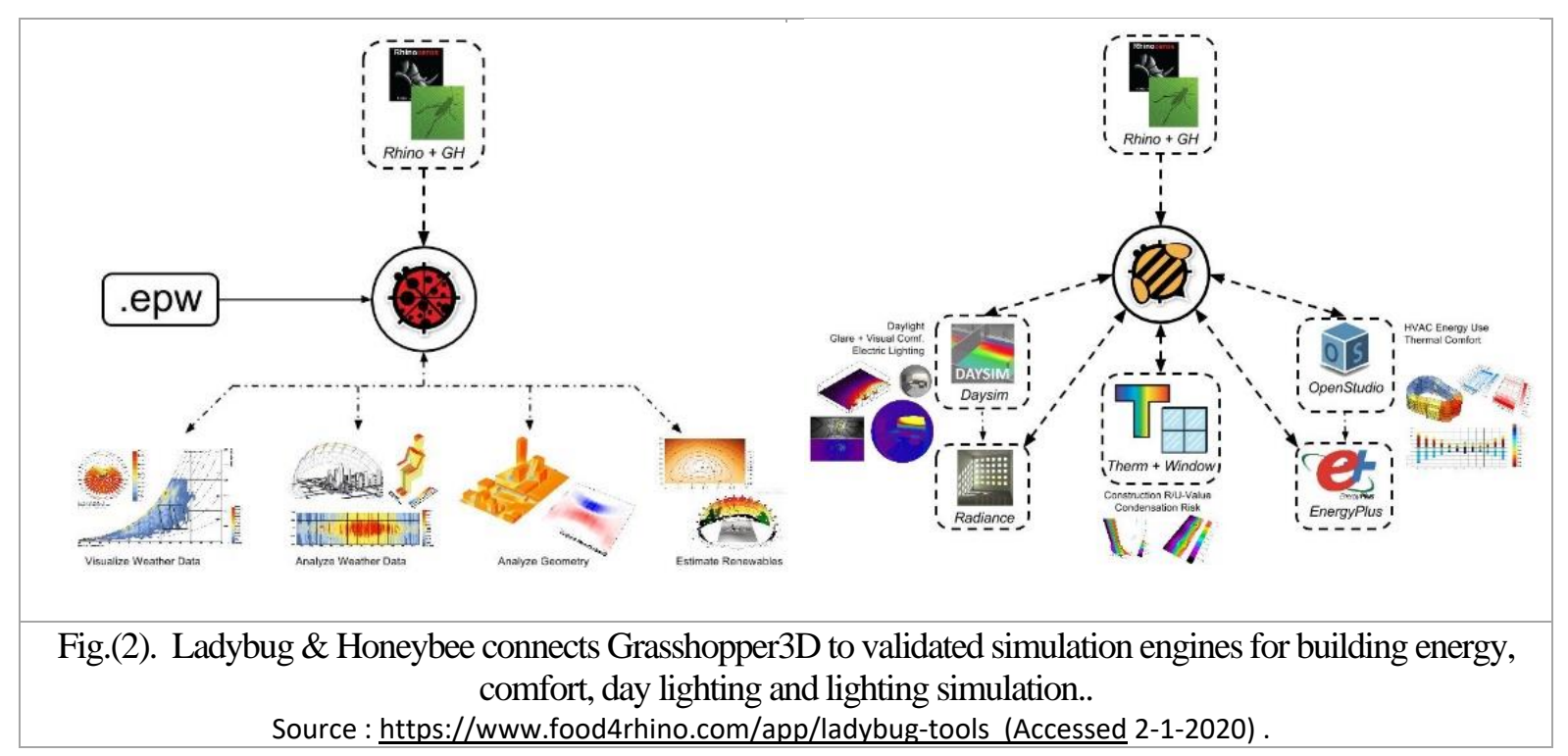

\section{- Genetic optimization algorithms}

Optimization in building design is an interesting point of study because of the integrated nature of both environmental and energy performance.It is used to extensively search the design alternatives looking for high performance solutions in terms of specified goals. The simulation-based optimization can overcome the drawbacks of evaluative trial and error approach. In order to combine parametric modeling with an optimization technique to support design explorations and form finding, Genetic algorithms (GAs) have been considered. GAs can perform a series of simulations in a multi-dimensional search space, increasing the relevance of the cases simulated. They are used to find the configuration that best matches desired performance goals. [8]

Genetic algorithms were shown to be effective in presenting new solutions to optimize light penetration and shading, taking into account many different aspects that influencing the performance of a façade [9].

The prediction of daylight levels by model-fitting was addressed by Coley and Crabb [10] using genetic algorithms. Park et al. [11] also maximized day lighting from a double-skin facade using non-linear programming. The principle was then developed into a real-time optimization program using genetic algorithms [12].

\section{Research Methodology}

The optimization process begins in 3D modeling software Rhinoceros [13], [3] and its parametric modeling plug-in Grasshopper. The building geometry is built with all the predetermined variables, whose values can be adjusted through sliders. The range of each design variable is determined based on designer's experience. The initial value of each design variable is set as the median value in the range, and the initial design geometry is generated. [14] 
Grasshopper plugins Ladybug and Honeybee [2] provide the functions of thermal, daylight and energy modeling. In the modeling process, the parametric building geometry is connected to the materials component in the Radiance [15] program, Then the building materials are connected to daylighting simulation component, with the input of weather files, daylighting sensor placement,and other simulation settings.

The building performance optimization process and the required software are illustrated in Fig. 3. There are four main steps in this approach. The first step is to identify design variables to be examined and to build a parametric design model. The second step is the development of thermal, daylight and energy model. The third step is integrated thermal, day lighting and energy simulation. The fourth step is the multiobjective optimization. After the optimization is terminated, the simulation data and optimized design solutions are further analyzed. [23]

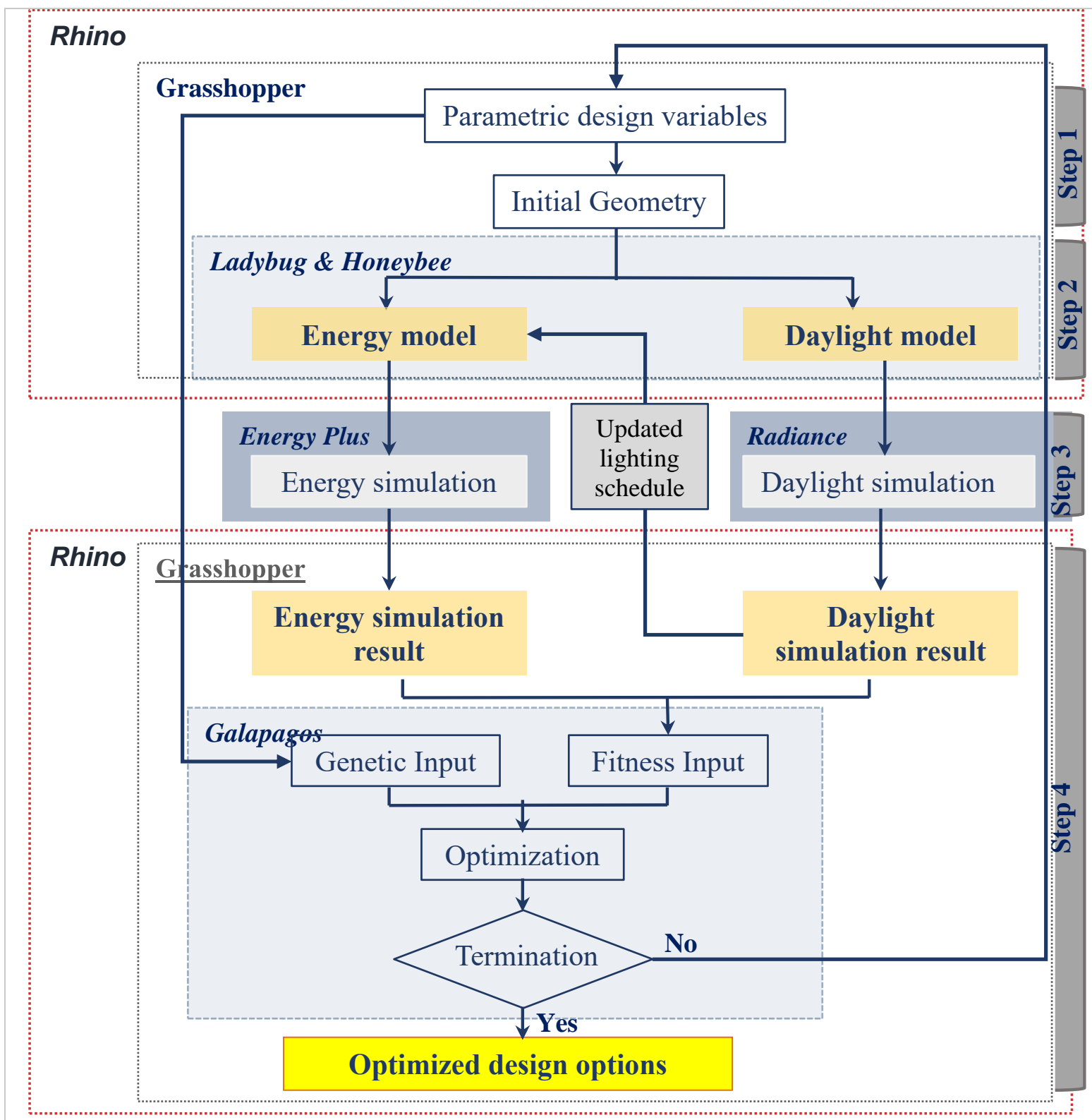

Fig.(3). Research Methodology framework for optimization process. Source : the researcher. 


\section{Model Setup}

Rhino/Grasshopper is one of the most widely used platforms that are used by designers today. There are already a number of environmental plugins developed for Rhino/Grasshopper. However, Ladybug offers several advantages that are currently not offered by existing Rhino/Grasshopper related environmental design plugins. The base case model is built in Grasshopper based on Rhinoceros 3D. [16]

The case study was chosen to be located in the city of Cairo, Egypt $\left(30^{\circ} \mathrm{N}\right.$ $\left.31^{\circ} \mathrm{E}\right)$. Also, as Cairo is the capital of Egypt and the center of industrial and administration work in Egypt, many fully glazed office buildings were built in the last few decades following the International Style. Cairo is characterized by a clear sunny sky for almost all the year round [16].

For the purpose of this study, the simulations were conducted using the standard Energy plus Weather data files (.EPW) of Cairo.

The occupancy schedule was chosen to be from 8:00 am till 5:00 pm, for five working days/week, which are the official working hours for the governmental sector as well as many private companies in Egypt.

The research proposes using an office unit with an area of about $100 \mathrm{~m} 2$ and a height of $4 \mathrm{~m}$ as a measurement model for research ideas to reach a building with thermal and energy efficiency.

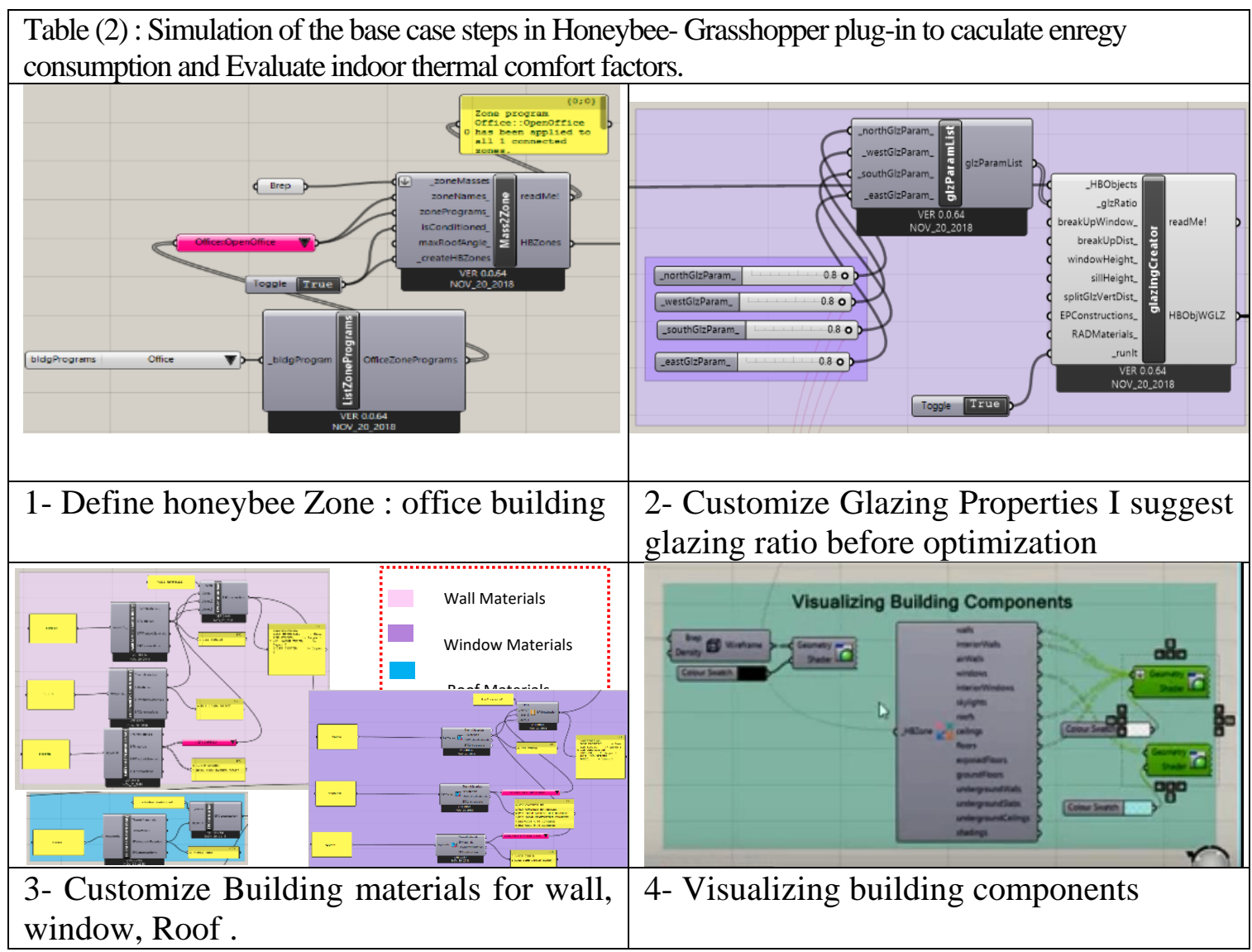




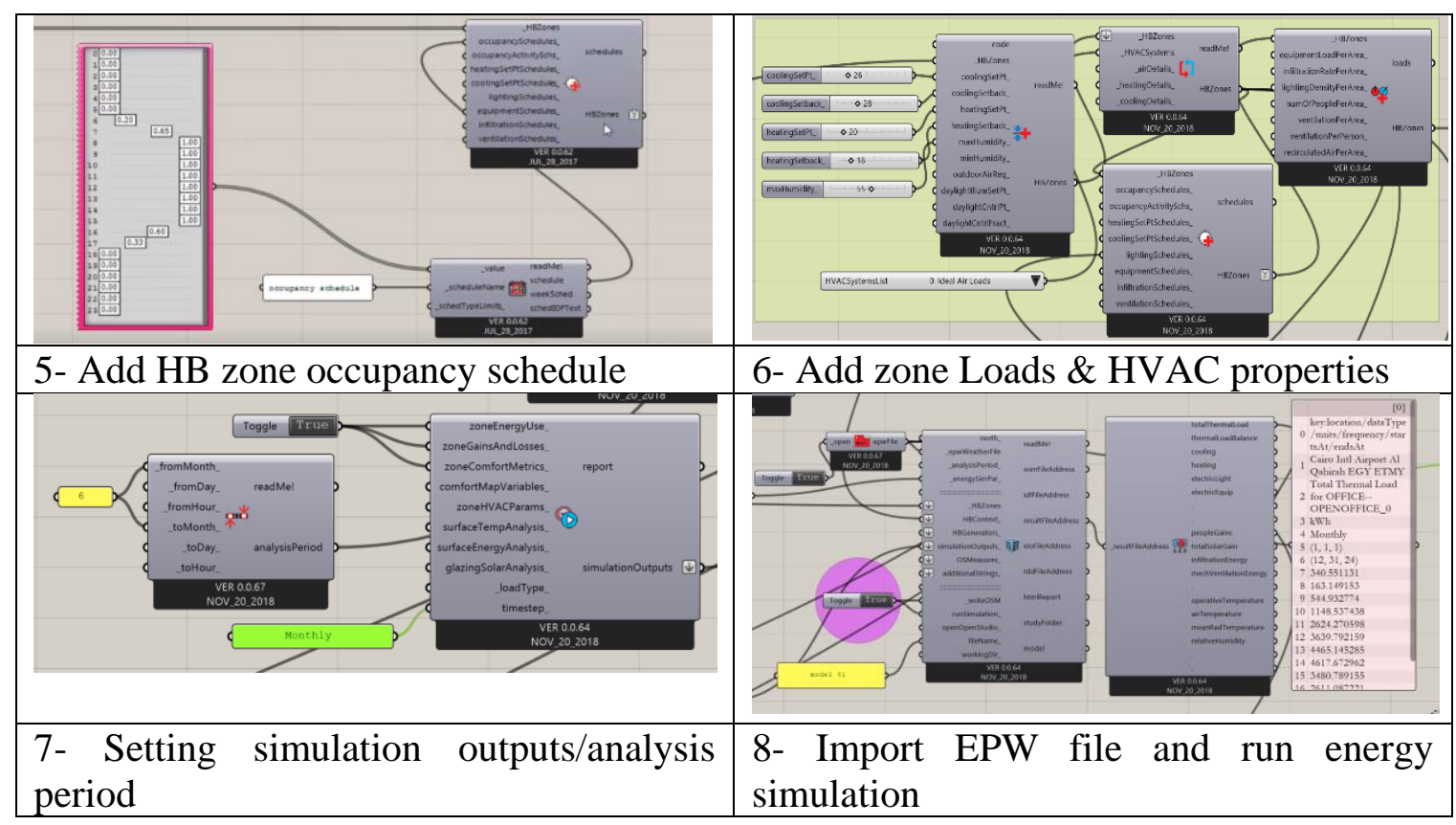

\section{Proposal one Optimization Building Shape \& Form}

The assessment of a building's energy performance as a design factor in the early design stages is a complex procedure which, nonetheless, can have a great impact on its energy consumption. Towards that, a number of tools and methods have been developed to address performance-related design questions, mostly using MultiObjective Optimization (MOO) Algorithms to improve the performance of day lighting, solar control, and natural ventilation strategies. [17]

It proposes using an office unit with an area of about 100 square meters and a height of $4 \mathrm{~m}$ as a measurement model to reach a building envelope with thermal efficiency.

The table (6.5) shows the impact of the building shape on energy consumption, lighting and heat gain that is responsible for achieving thermal and optical comfort. It also shows the effect of orientation for the same shape and the same dimensions.

\begin{tabular}{|c|c|c|c|c|}
\hline \multicolumn{3}{|c|}{ Table (3): Optimization of form \& orientation of building for saving energy and minimize solar gain (KWH). } \\
\hline $\begin{array}{c}\text { Shape } \\
\text { \&orientation }\end{array}$ & & & \\
\hline Ratio & $1: 1,10^{*} 10,0 \mathrm{deg}$. & $1: 1,10 * 10,0 \mathrm{deg}$. & $1: 1,10^{*} 10,0 \mathrm{deg}$. & $1: 1,10 * 10,45 \mathrm{deg}$ \\
\hline thermal & 28943.8 & 36960.5 & 45661.6 & 46470.0 \\
\hline lighting & 3278.5 & 2458.4 & 3191.5 & 3191.5 \\
\hline Total energy & $\mathbf{3 2 2 2 2 . 3}$ & $\mathbf{3 9 4 1 8 . 9}$ & $\mathbf{4 8 8 5 3 . 0}$ & $\mathbf{4 9 6 6 1 . 5}$ \\
\hline Solar gain & 30370.5 & 61658.7 & 82982.7 & 84748.9 \\
\hline
\end{tabular}




\begin{tabular}{|c|c|c|c|c|}
\hline $\begin{array}{c}\text { Shape } \\
\text { \&orientation }\end{array}$ & & & & \\
\hline Ratio & $1: 2,7 * 14,0$ deg. & $1: 2,7 * 14,45 \mathrm{deg}$. & $1: 2,7 * 14,90$ deg. & $1: 2,7 * 14,0135 \mathrm{deg}$ \\
\hline thermal & 43791.3 & 46977.7 & 49266.1 & 47994 \\
\hline lighting & 3127.64 & 3127.64 & 3127.64 & 3127.64 \\
\hline Total energy & 46918.91 & 50105.31 & 52393.71 & 51121.67 \\
\hline Solar gain & 81413.9 & 88161.1 & 92797.7 & 89732.7 \\
\hline $\begin{array}{c}\overbrace{\text { Shape }}^{\mathrm{N}} \\
\text { \&orientation }\end{array}$ & & & & \\
\hline Ratio & $1: 3,6 * 17,0$ deg. & $1: 3,6 * 17,45$ deg. & $1: 3,6 * 17,90 \mathrm{deg}$. & $1: 3,6 * 17,135 \mathrm{de}$ \\
\hline thermal & 45741.2 & 50258.1 & 54016 & 51766.7 \\
\hline lighting & 3255.3 & 3255.3 & 3255.3 & 3255.3 \\
\hline Total energy & 48996.54 & 53513.44 & 57271.28 & 55021.97 \\
\hline Solar gain & 86393.7 & 96110.5 & 104290 & 98584.2 \\
\hline$\underset{\substack{\text { Shape } \\
\text { \&orientation }}}{\stackrel{\mathrm{N}}{\Theta}}$ & & & & \\
\hline Ratio & $2: 3,8 * 12,0 \mathrm{deg}$. & $2: 3,8^{*} 12,45 \mathrm{deg}$ & $2: 3,8 * 12,90 \mathrm{deg}$ & $2: 3,8 * 12,135 d$ \\
\hline thermal & 43246.7 & 45320.4 & $\leq \neg \leq \varepsilon \cdot, V$ & 45885.9 \\
\hline lighting & 3063.81 & 3063.82 & 3063.8 & 3063.8 \\
\hline Total energy & 46310.54 & 48384.18 & $\varepsilon 90 . \varepsilon, 0$ & 48949.71 \\
\hline Solar gain & 79735 & 84297 & 86229.6 & 85227 \\
\hline
\end{tabular}

Although the lighting consumption of the same forms and orientation of the model were differ slightly, the effect of the shape and orientation has a significant impact on the cooling and heating loads and the building's solar radiation.

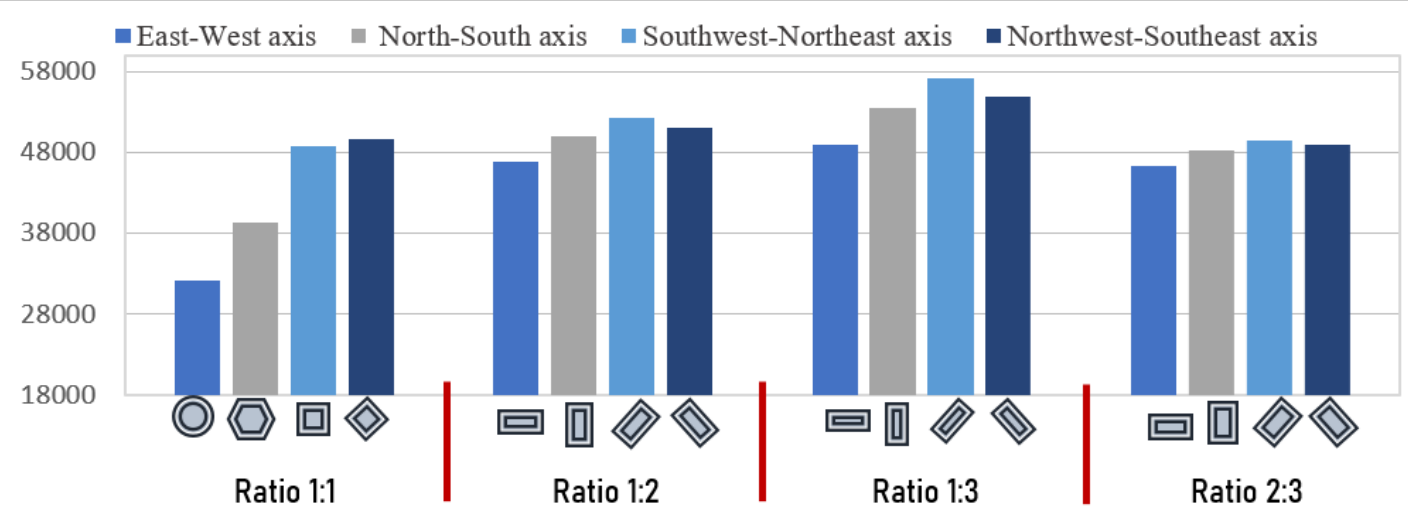

Fig.(4).Investigate the impact of building orientation on the amount of energy consumption and solar gain in the building envelope. Source: Simulation by the researcher . 


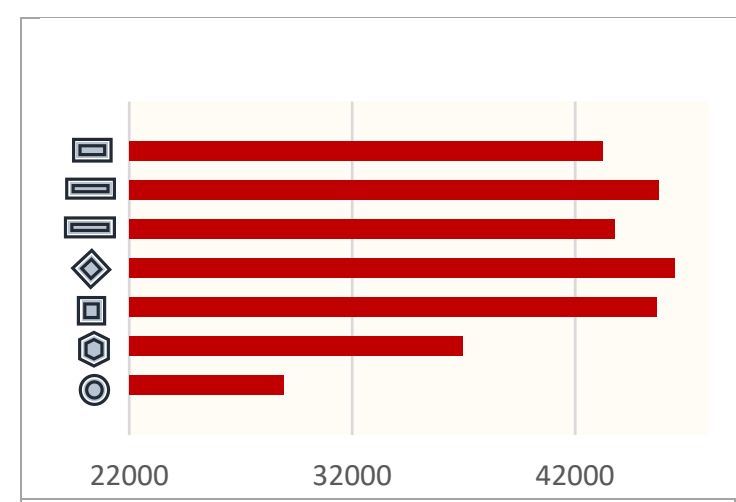

Fig.(5).Annual total thermal loads for cooling and Heating loads rankings for different plan shapes.Source : Simulation by the researcher

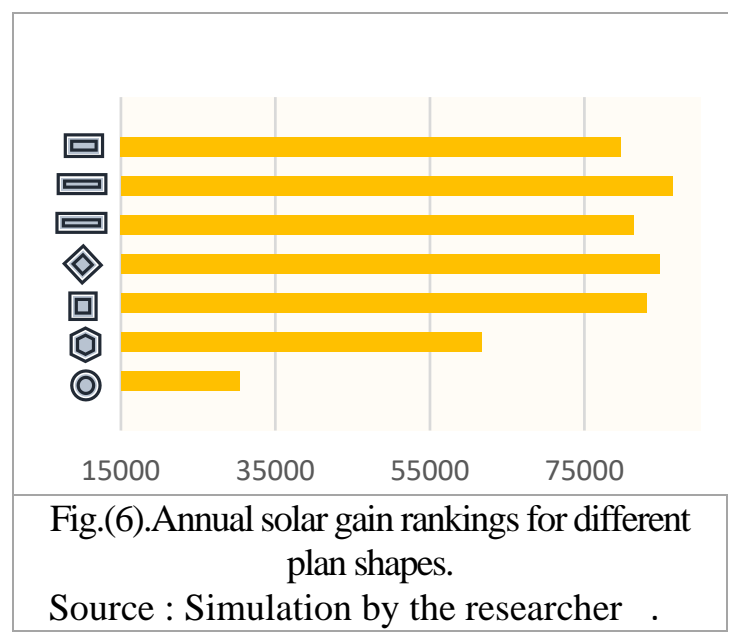

The study verified that the best shape is round, followed by the hexagon, as they have a smaller perimeter to area ration, are less exposed to the sun, and thus gain less heat. When examining the buildings to reach thermally efficient office Building envelope in Egypt requires that the form is prevalent in the design of administrative buildings in Egypt (as shown in Fig 7). So that the research can address the problems of buildings already in the design stage or make an adjustment to the existing ones in order to reduce the cooling load. Therefore, the rectangular shape was chosen.
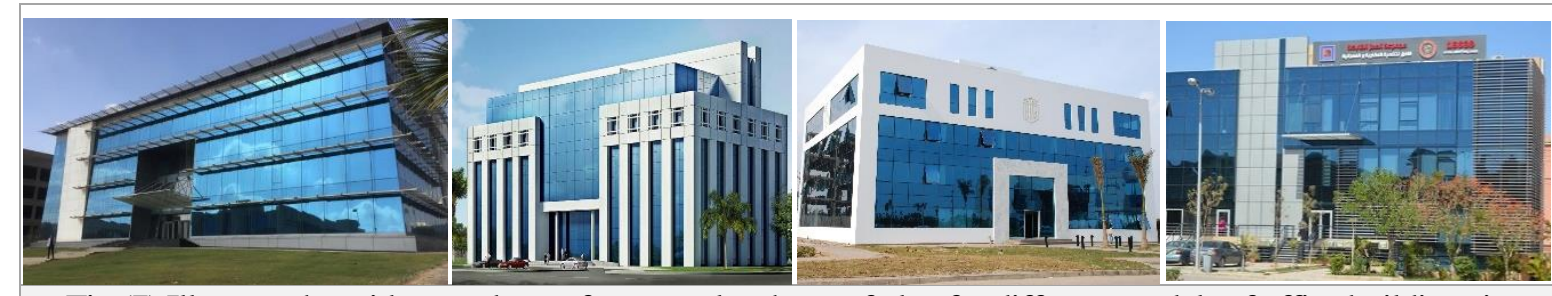

Fig.(7).Illustrate the widespread use of rectangular shape of plan for different models of office buildings in Cairo. Source : https://www.google.com.eg/ (Accessed 2-2-2020) .

Therefore, for the orientation optimization, the rectangular shape was chosen. For this step different orientations were examined (North-South, East-West and Northwest-Southeast, Southwest-Northeast).

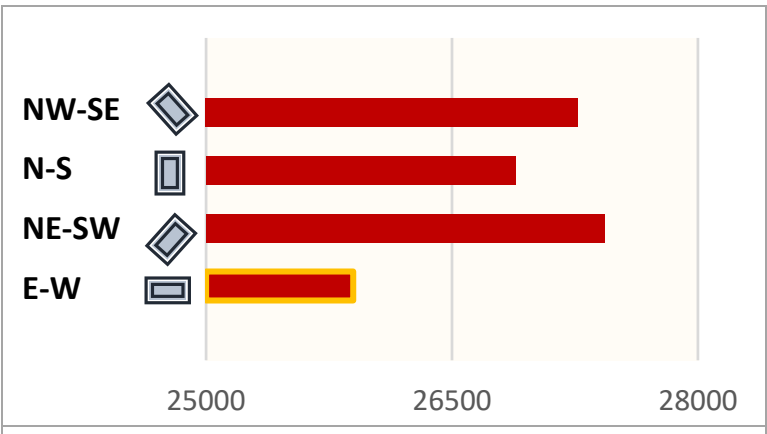

Fig.(8).Annual total thermal loads for cooling and Heating loads rankings for different plan shapes.

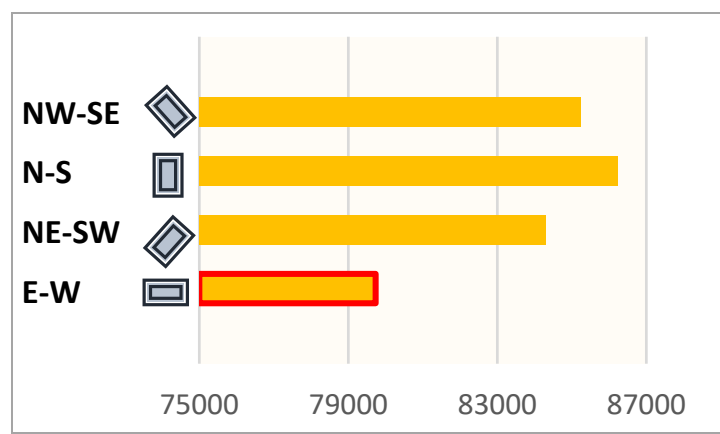

Fig.(9).Annual solar gain rankings for different plan shapes. Source: by the researcher .

The solar gains chart (Fig. (9)) indicates that greater exposure of the facade towards the east and west directions leads to increased solar gains, since the incidence angle is small, thus the solar radiation penetrates the whole floor plan. On the other 
hand exposure of the long side of the facade towards the south leads to diminished solar gains due to the fact that the steep incidence angle of the solar radiation limits the radiation from reaching deep in the floor-plan.

\subsection{Model description}

Since the results of simulation proved that the north and south side the solar radiation is lower than on the east and west side, this orientation is chosen for further treatments. As shown in the (Fig 6.34).

The base case model is a fully glazed

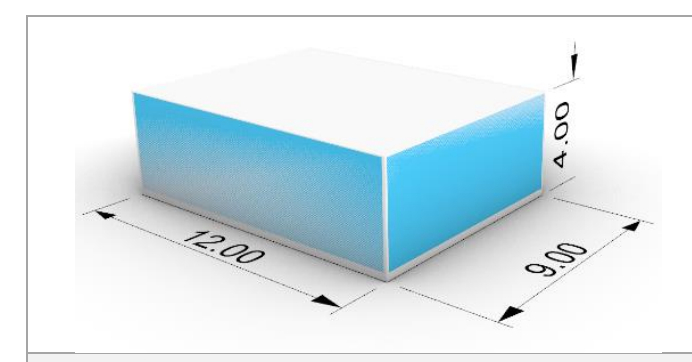

Fig.(10). Isometric of the base case model of office space.Source : the researcher

office unit and consists of floor area of $100 \mathrm{~m} 2$ distributed $8^{*} 12 \mathrm{~m}$ as shown in Fig. 10. The outer walls consist of $25 \mathrm{~cm}$ of concrete blocks covered on both sides by a 2 $\mathrm{cm}$ layer of mortar, the $U$ value of these walls is $2.34 \mathrm{~W} /(\mathrm{m} 2 \cdot \mathrm{K})$, their external solar absorptance is 0.6 which is the solar absorptance of concrete. The roof is composed of a hollow-core slab of $20 \mathrm{~cm}$ covered from the top by a $5 \mathrm{~cm}$ layer of mortar above which tiles of a thickness of $2 \mathrm{~cm}$ are superimposed, and covered from the bottom by $2 \mathrm{~cm}$ of gypsum plaster. The $\mathrm{U}$ value of the roof is $2.21 \mathrm{~W} /(\mathrm{m} 2 \cdot \mathrm{K})$, their external solar absorptance is 0.75 which is the solar absorptance of dark red tiles. All glazed areas of the reference building consist of single glazing with a $U$ value of 5.74 $\mathrm{W} /(\mathrm{m} 2 \cdot \mathrm{K})$ and $\mathrm{g}$-value of 0.87 .

\subsection{Energy Performance and Comfort Analysis}

The simulation is performed using Energy Plus, which is a building thermal performance simulation program performed on a sub-hourly level. The features of Energy Plus make it ideal for this and other studies to assess thermal comfort in building [18]. As it is based on an essential heat balance procedure where surface temperatures are a part of the solution, the radiant effect of surfaces on thermal comfort can be addressed. Without knowledge of the inside surface temperatures, thermal comfort calculations are not possible. [19], [20]

In hot climates, buildings are overheated during the day due to solar heat gain through the building envelope and solar penetration through windows. [22]

A study has shown that in Cairo, a comfortable indoor ambient temperature should be in the range of $22^{\circ} \mathrm{C}$ to $27^{\circ} \mathrm{C}$ for normal clothing. Humidity of the air should be in the range of $30 \%$ to $60 \%$ and the optimum air movement in the range $0.5 \mathrm{~m} / \mathrm{s}$ to $1.5 \mathrm{~m} / \mathrm{s}$ depending on occupant activity (for a naturally ventilated environment). [24]

\section{- Energy consumption in the base case}

The monthly energy demand for cooling and heating of the Base case before implementing any passive or active cooling techniques. The cooling and heating demands were calculated using set points of $26^{\circ} \mathrm{C}$ and $20^{\circ} \mathrm{C}$ respectively according to ISO 7730. For Cairo City, the monthly cooling demand peaked at $6646.0 \mathrm{kWh} / \mathrm{m} 2$ 
in July and the total yearly cooling demand reached $43150.8 \mathrm{kWh} / \mathrm{m} 2$. While the heating demand is predominating with a peak monthly heating demand of nearly 29 $\mathrm{kWh} / \mathrm{m} 2$ in January and a total yearly heating demand of $74.4 \mathrm{kWh} / \mathrm{m} 2$.

Therefore, the research focused from its beginning on the cooling techniques, also simulation proved that the heating loads were not as important as the cooling loads in a warm climate like Cairo.

It is observed in Fig (11) that total energy consumption increases in May, June, July, August, September, and October due to increasing solar radiation in these months . The total yearly energy consumed by the base case model, is 46289.18 $\mathrm{kWh} / \mathrm{y}$ shows also that the energy consumption in summer period is the highest consumption of energy.

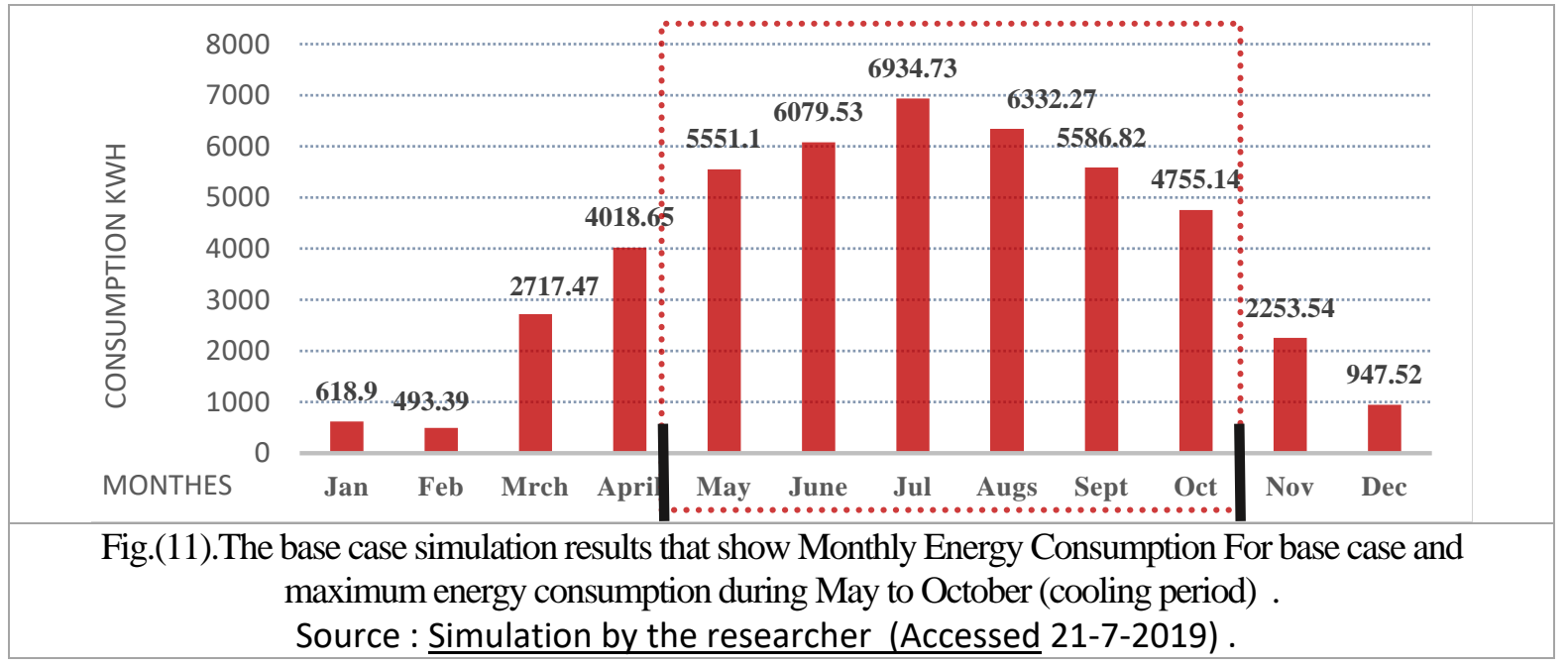

\section{- Temperature}

Figure 9 shows outdoor and indoor temperatures for the hottest day of summer which are the 21th of August for Cairo. These hottest day was determined according to indoor temperatures. Note that the temperature of the Base case peaked at $37{ }^{\circ} \mathrm{C}$. which is very uncomfortable. During the coldest day of winter peaked at $16.5^{\circ} \mathrm{C}$., which is the 8th of January for model studied, the outdoor temperature reached a minimum of $15{ }^{\circ} \mathrm{C}$. The coldest day was determined according to indoor temperatures.

\section{- Discomfort Hours}

In this study, thermal comfort was assessed through the calculation of discomfort hours caused by overheating and overcooling in addition to unhealthy relative humidity. For the model, Results of simulation shows that the number of overheating hours was about 6041 from 8760 hours over the year. On the other hand, the sum of overcooling hours over a year was about only 336 hours per year.

\section{Proposal Two Optimization Window to Wall Ratio}

Window to Wall Ratio (WWR)L: Glazing percentage stands for the amount of the glazing area to the area of the wall which is very effective in the heat transfer of 
buildings. In case this amount is reduced, less heat will be transferred outside (heat loss). On the other hand, greater percentage of glazing lets more solar radiation in which leads to a greater heat gain. Although it is the main source of natural lighting, there should be an optimal amount so that the amount of heat gain is minimized, without sacrificing proper level of natural lighting. [25]

\subsection{Model description}

In order to determine the optimum percentage of window size in the external facades of an office model, the model dimensions were considered to be $8 \mathrm{~m} \mathrm{x} 12 \mathrm{~m}$ with a height of $4 \mathrm{~m}$; this model has an eastern-western orientation axis, as illustrated in Figure 3. In this research, grasshopper software was used to simulate the building. This software has the Energy Plus analysis engine and is able to calculate the solar heat gain and energy consumption related to lighting, heating and cooling load. The lighting level has been considered 300 Lux based on the ASHRAE standard for office buildings.

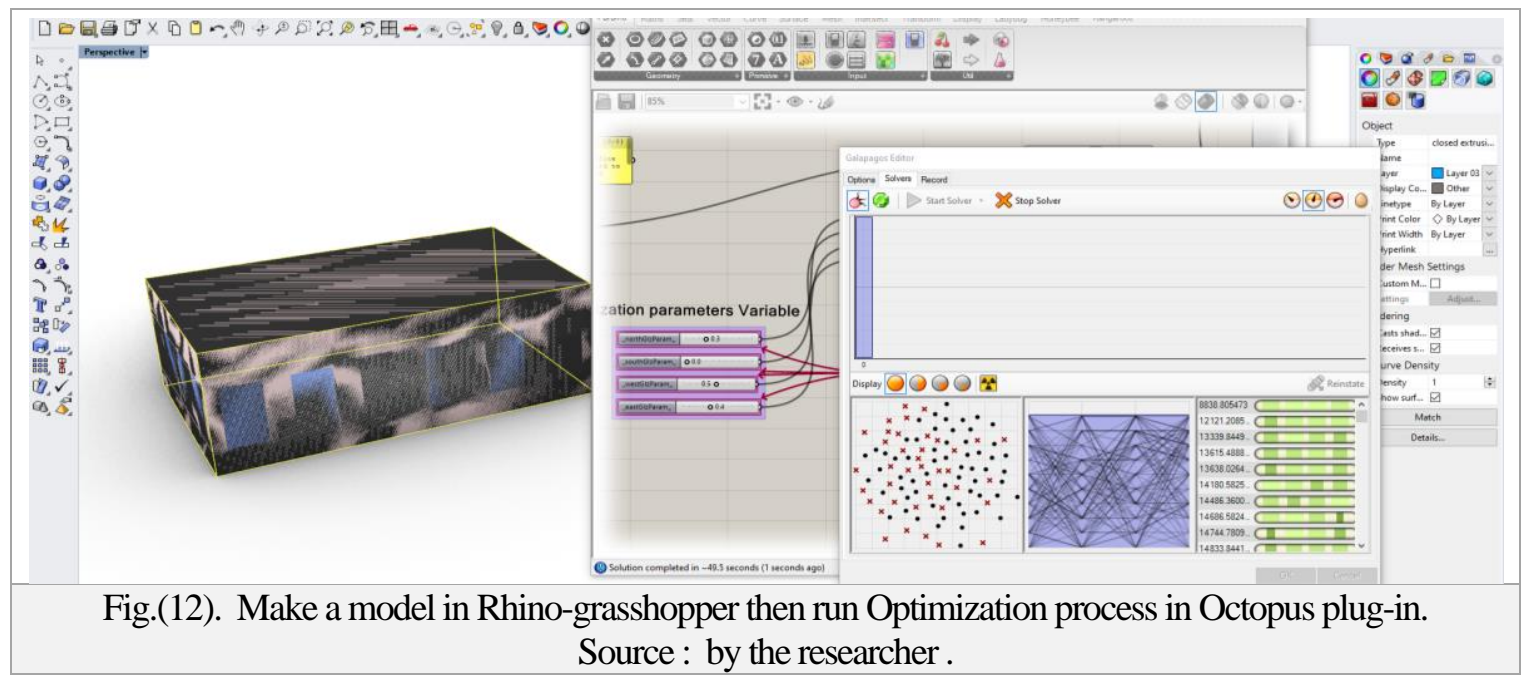

\subsection{Energy Performance and Comfort Analysis}

The annual thermal and lighting consumption of the model for various window percentages is illustrated for Cairo. When increasing the percentage of windows in all facades, the amount of light consumption decreased because more natural light entered the indoor environment, which leads to a decrease in lighting consumption. But the cooling loads increase by increasing the percentage of windows.

For this variable, 8 different values were researched: $10 \%, 20 \%, 30 \%, 40 \%$, $50 \%, 60 \%, 70 \%$, and $80 \%$. A $10 \%$ window to wall ratio is expected to reduce cooling loads, but increase electric lighting loads, whereas an $80 \%$ WWR is expected to increase cooling loads and decrease electric lighting loads, since it refers to almost a fully glazed facade that allows more daylight in the building. 


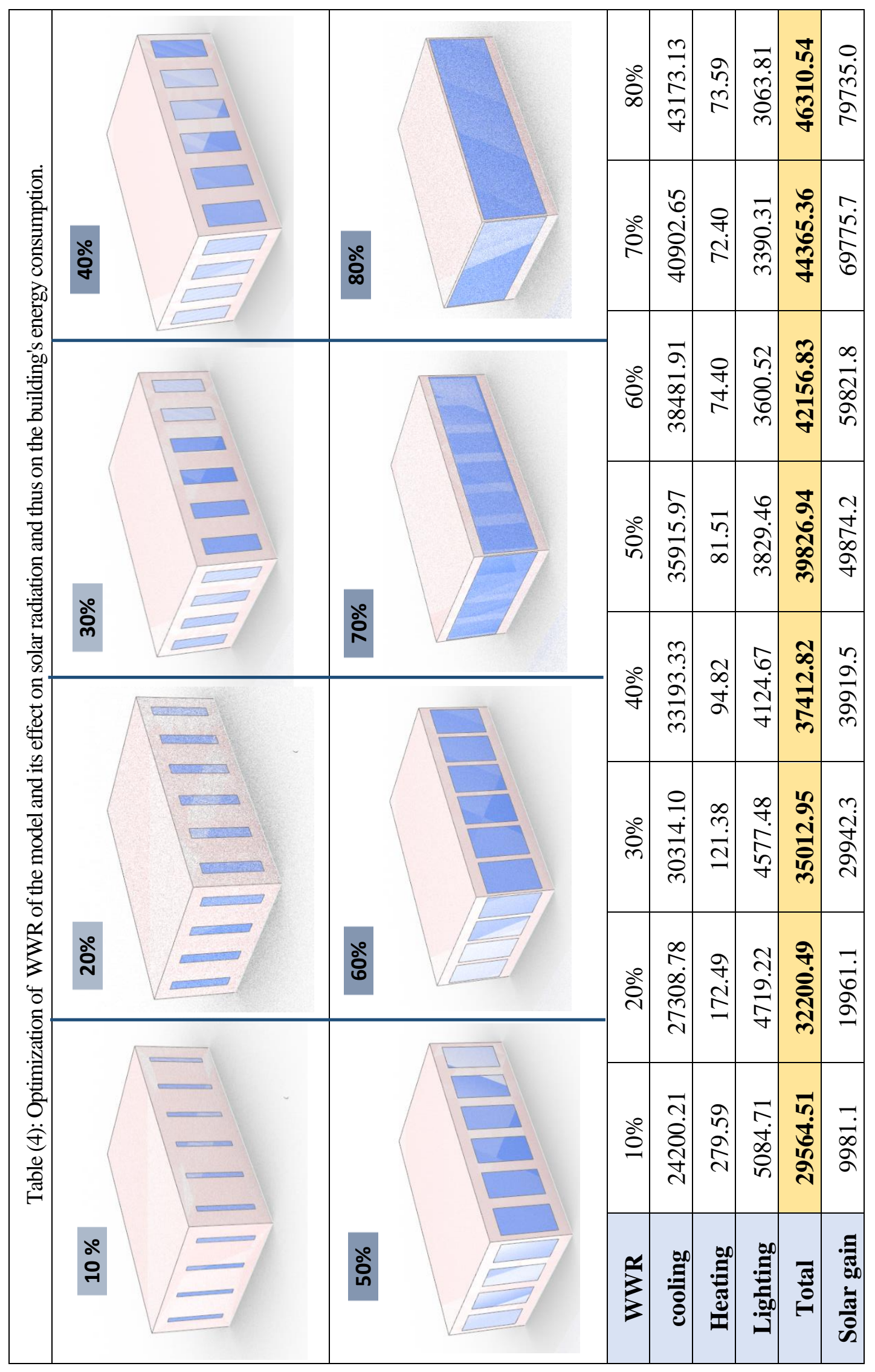


The glazing ratio is the same for all directions for this first optimization round. The chart (Fig. 13) illustrates the effect of WWR on the energy demand and comfort levels. Small windows have a positive effect on reducing energy demand, but also increasing comfort levels in a building, since they lead to reduced solar heat gains and thus reduced cooling loads.

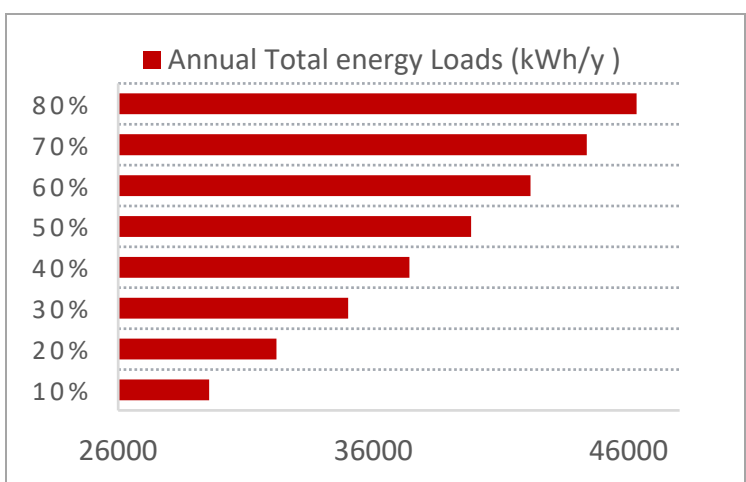

Fig.(1 $\left.{ }^{\Upsilon}\right)$.Annual total energy loads for cooling, Heating loads rankings for different WWR.

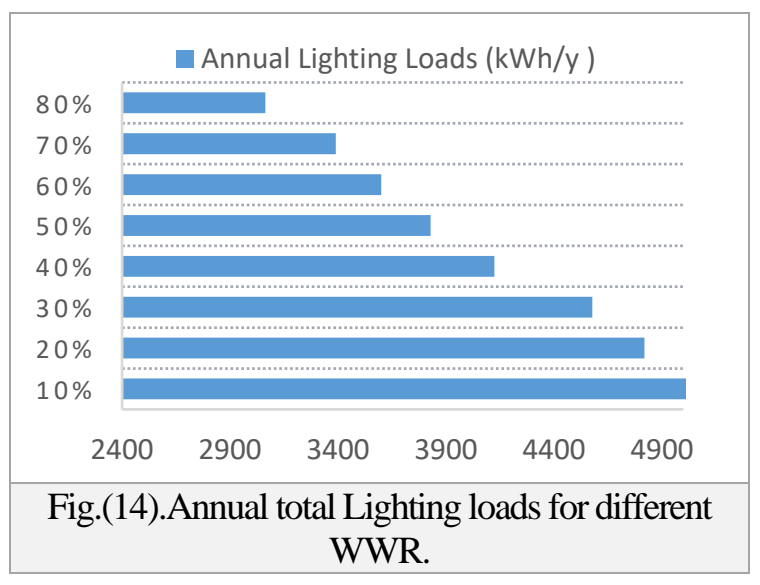

The percentage of windows area in the four north, south, east, and west facades of the building has been investigated from $10 \%$ to $80 \%$ with a $10 \%$ step. In order to determine the optimum percentage of a building facade, at first all facades were considered the percentage of the window on that facade was changed and the data of solar heat gain, cooling load, heating load, and the annual lighting consumption of each mode were determined.

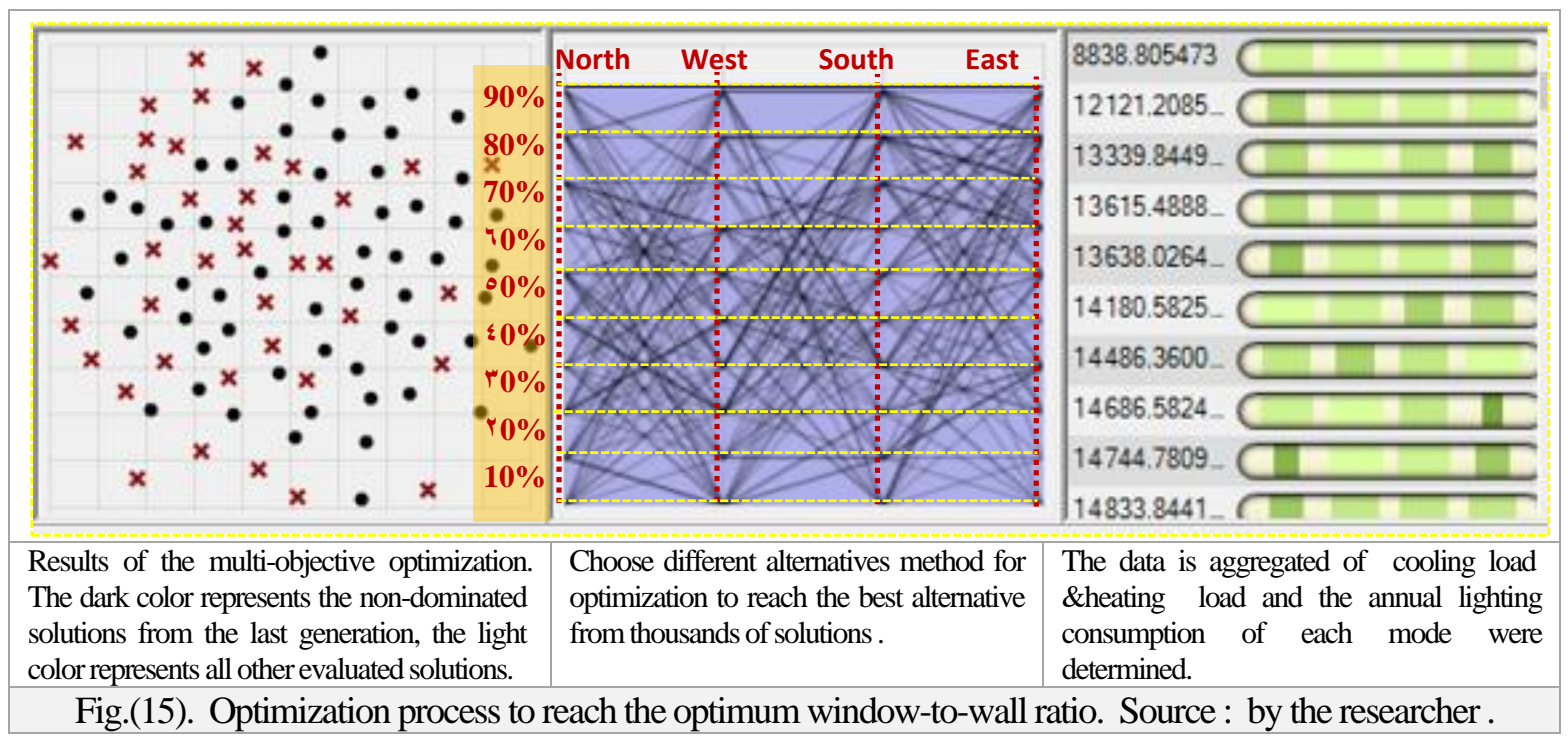

Usually, in the design of static buildings to decrease the amount of solar heat gain, at the southern facade small windows are used and at the northern facade large windows are utilized. The impact of increasing the northern window areas and reducing the southern windows in static buildings was examined. The results of this study revealed that the dimensions of the energy-efficient window had a high impact on the cooling load [24]. 
Algorithms optimization is used to optimize the envelope design of buildings. In simulations that were conducted with optimization, the genetic algorithm is coupled to a building engine in order to select optimal values for window-to-wall ratio (WWR) parameters for the minimum energy consumption of buildings. The optimum WWR in a building it was $60 \%$ in the north façade but $40 \%$ in the south façade and $50 \%$ in the West and East façade.

\section{- Energy consumption in the proposal two}

After reaching the optimum WWR, The results of the proposal should be compared to the previous situation and verification of energy saving towards thermal comfort. By comparing the total energy for cooling, heating and lighting energy demands of the new model to the Base case model. The cooling energy demand reduced by $18.1 \%$, but it increased the heating demand by $16 \%$. However, the lighting remains constant due to the achievement of the required levels of natural lighting, and it was not called to operate the artificial lighting.

\begin{tabular}{|c|c|c|c|}
\hline \multicolumn{4}{|c|}{ Table (5). Comparing the energy consumption for cooling, heating and lighting energy demands of the new } \\
model to the Base case model.
\end{tabular}

The total yearly energy consumed by the base case model for thermal energy (cooling and heating), was $46289.18 \mathrm{kWh} / \mathrm{y}$ and after optimizing the glazing ration became $38496.53 \mathrm{kWh} / \mathrm{y}$. the next fig(16) shows Monthly Energy Consumption For thermal energy (cooling and heating) for previous situation and new proposal model . This saved energy by $16.8 \%$. These results show that regarding the total energy demand, how the optimal design of the proportions of the building envelope openings is important.

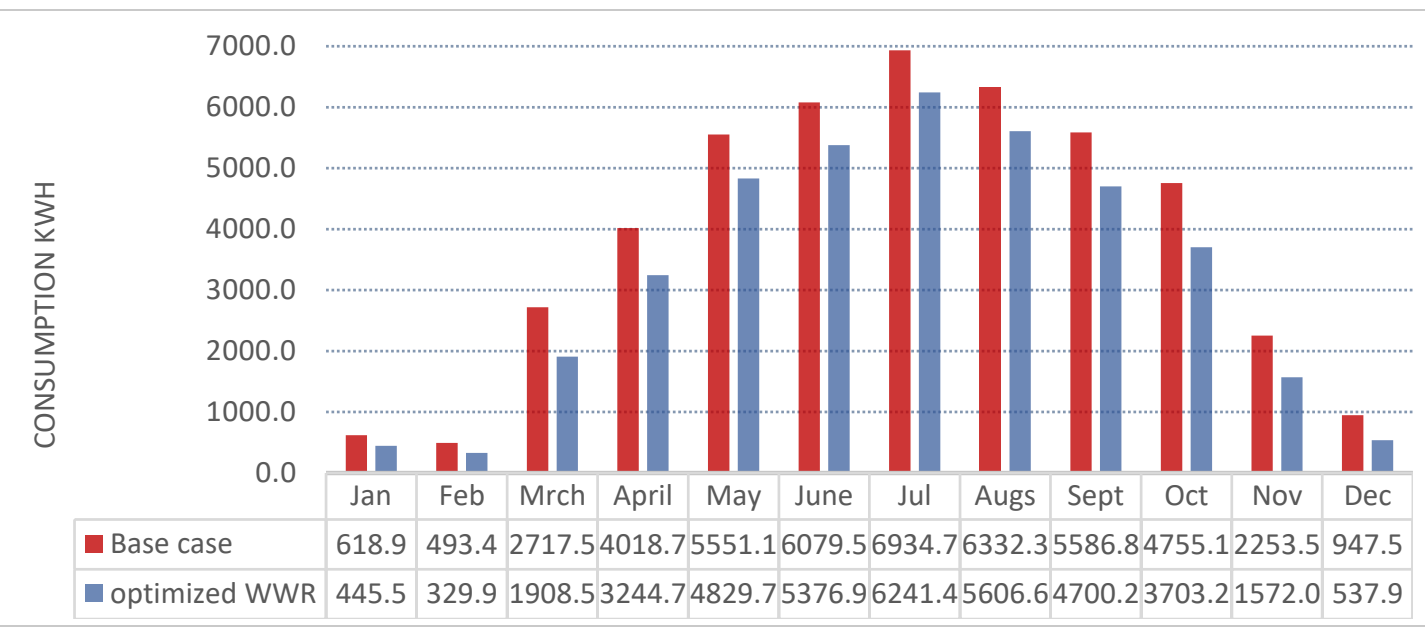

Fig.(16).Monthly total Energy Consumption for (cooling, heating and lighting) for previous situation (Base case) and new proposal model (model optimized WWR) . source : the researcher. 


\section{- Temperature}

The results show an offset of the maximum indoor air temperature in the Optimized WWR model was reached $32.1^{\circ} \mathrm{C}$ as shown in fig 16 , where a decrease of $5^{\circ} \mathrm{C}$ was observed compared to the base case model. On the other hand, the minimum temperature peaked at $18.1^{\circ} \mathrm{C}$ was increased by $1.6^{\circ} \mathrm{C}$.

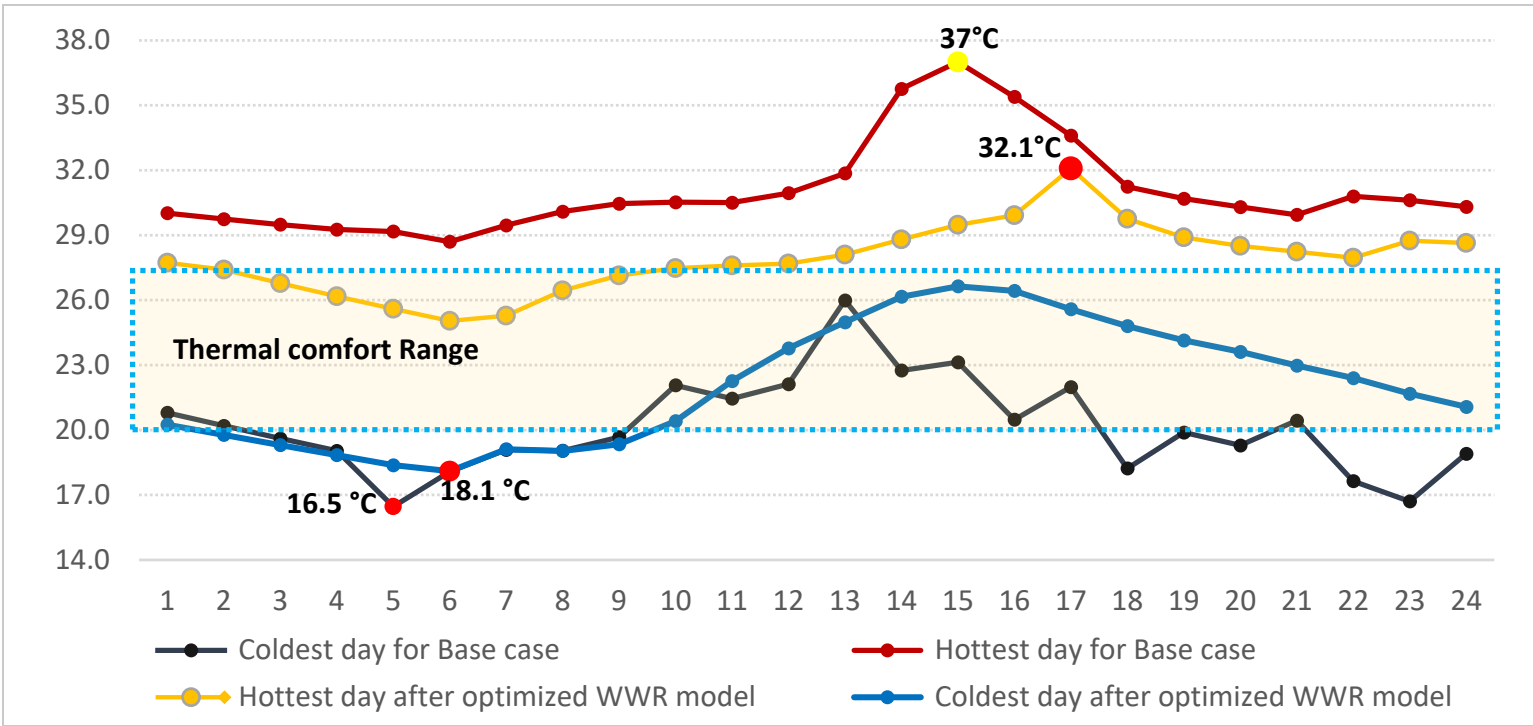

Fig.(17).The simulation results show Max \& Min Indoor Temp for Hottest \& coldest day to compare with Thermal comfort range and after optimized WWR. Source $: \underline{\text { by the researcher. }}$.

- Discomfort Hours

Table 22 shows the number of overheating hours of the model after optimization of glazing ratio, the researcher noted that there are 5300 hours of overheating (based on $27^{\circ} \mathrm{C}$ ) and that the temperature exceeds $30{ }^{\circ} \mathrm{C}$ only 1022 hours throughout the year compared to 6041 hours of overheating for the base model which shows a clear improvement of the thermal comfort.

On the other hand, the table also shows that the number of overcooling hours is about 411 hours compared to the base model which has 336 hours of overcooling, this leads to the conclusion that even if the energy demand for heating is greatly reduced, the number of hours when the temperature is below $20{ }^{\circ} \mathrm{C}$ has not been improved. But the researcher noted from the results that many temperatures may reach between 18 and 19 degrees, so the difference is no longer significant .

\begin{tabular}{|c|c|c|c|}
\hline \multicolumn{4}{|c|}{ Table (6) count discomfort hours in new model to measure achieving thermal comfort. } \\
\hline Model & Overheating Hours $>\mathbf{2 7}^{\circ} \mathrm{C}$ & Overheating Hours $>\mathbf{3 0}^{\circ} \mathrm{C}$ & Overcooling Hours $<\mathbf{2 0}^{\circ} \mathbf{C}$ \\
\hline Base Case & 6041 & 2231 & 336 \\
\hline WWR model & 5300 & 1022 & 411 \\
\hline
\end{tabular}

\section{Results and discussion}

The results indicate that the proportion of openings have a major impact on reducing energy consumption and reducing discomfort hours in the building. It also affected improving temperatures by 5 degrees. 


\section{Conclusion}

In the pursuit of a sustainable society, the improvements of environmental performance in buildings have a critical impact. It is essential to have suitable tools available at the conceptual design stage to assist designers to find efficient alternative designs. This paper proposed optimization model that can be used to determine optimum or near optimum shape, orientation and the window to wall ratio (WWR) of the building in office model in Cairo climate.

Finally, the optimization results of the building design multi-objective optimization model for the case study show significant improvements of the energy performance, and insignificant improvement of indoor thermal and optical comfort performance.

The simulation results suggest that the building design multi-objective optimization model is an effective tool for building optimization design.

\section{References}

[1] Attia, S. (2010). Building performance simulation tools: selection criteria and user survey. Architecture et climat..

[2] Roudsari, M. S., Pak, M., \& Smith, A. (2013, August). Ladybug: a parametric environmental plugin for grasshopper to help designers create an environmentally-conscious design. In Proceedings of the 13th international IBPSA conference held in Lyon, France A.

[3] McNeel, R. (2010). Grasshopper-Generative Modeling with Rhino, McNeel North America, Seattle, USA.

[4] Day, M. (2010). 2000-2010. Rhino Grasshopper, AEC Magazine, X3DMedia..

[5] Lagios, K., Niemasz, J., \& Reinhart, C. F. (2010). Animated building performance simulation (ABPS)-linking Rhinoceros/Grasshopper with Radiance/Daysim. Proceedings of SimBuild, 4(1), 321-327..

[6] Ward, G. J. (1994, July). The RADIANCE lighting simulation and rendering system. In Proceedings of the 21st annual conference on Computer graphics and interactive techniques (pp. 459-472)..

[7] Reinhart, C. F., \& Walkenhorst, O. (2001). Dynamic RADIANCE-based Daylight Simulations for a full-scale Test Office with outer Venetian Blinds. Energy \& Buildings, 33(7), 683-697..

[8] Turrin, M., Von Buelow, P., \& Stouffs, R. (2018). Design explorations of performance driven geometry in architectural design using parametric modeling and genetic algorithms. Advanced Engineering Informatics, 25(4), 656-675..

[9] Zemella, G., De March, D., Borrotti, M., \& Poli, I. (2011). Optimised design of energy efficient building façades via evolutionary neural networks. Energy and Buildings, 43(12), 3297-3302..

[10] Soong, B. H., Kandasamy, N. K., Karunagaran, G., Spanos, C., \& Tseng, K. J. (2018). Smart lighting system using ANN-IMC for personalized lighting control and daylight harvesting..

[11] Park, C. S., Augenbroe, G., \& Messadi, T. (2013, August). Daylighting optimization in smart facade systems. In Proceedings of the Eighth International IBPSA Conference (Vol. 107)..

[12] Yoon, S. H., Park, C. S., \& Augenbroe, G. (2011). On-line parameter estimation and optimal control strategy of a double-skin system. Building and Environment, 46(5), 1141-1150.. 
[13] Srisamranrungruang, T., \& Hiyama, K. (2020). Balancing of natural ventilation, daylight, thermal effect for a building with double-skin perforated facade (DSPF). Energy and Buildings, 109765..

[14] Fang, Y., \& Cho, S. (2019). Design optimization of building geometry and fenestration for daylighting and energy performance. Solar Energy, 191, 7-18..

[15] Grande, E., Imbimbo, M., \& Tomei, V. (2018). Role of global buckling in the optimization process of grid shells: Design strategies. Engineering Structures, 156, 260-270..

[16] Hammad, H., Abd Elkader, M., \& Fagal, A. (2017). Investigating the Thermal Comfort Conditions in an Existing School Building in Egypt. submitted to Assiut Engineering University Journal..

[17] Peel, M. C., Finlayson, B. L., \& McMahon, T. A. (2007). Updated world map of the KöppenGeiger climate classification. Hydrology and earth system sciences discussions, 4(2), 439-473..

[18] Touloupaki, E., \& Theodosiou, T. (2017). Optimization of building form to minimize energy consumption through parametric modelling. Procedia environmental sciences, 38, 509-514..

[19] Zhang, J. (2020, January). Research on building energy efficiency based on energyplus software. In IOP Conference Series: Earth and Environmental Science (Vol. 432, No. 1, p. 012013). IOP Publishing..

[20] Zhu, J., Tong, L., Li, R., Yang, J., \& Li, H. (2020). Annual thermal performance analysis of underground cave dwellings based on climate responsive design. Renewable Energy, 145, 1633-1646..

[21] Teixeira, H., Gomes, M. G., Rodrigues, A. M., \& Pereira, J. (2020). Thermal and visual comfort, energy use and environmental performance of glazing systems with solar control films. Building and Environment, 168, 106474..

[22] Somasundaram, S., Chong, A., Wei, Z., \& Thangavelu, S. R. (2020). Energy saving potential of low-e coating based retrofit double glazing for tropical climate. Energy and Buildings, 206, 109570..

[23] Standard, A. S. H. R. A. E. (2010). Standard 55-2010, Thermal environmental conditions for human occupancy. American Society of Heating, Refrigerating and Air Conditioning Engineers..

[24] Gan, V. J., Lo, I. M., Ma, J., Tse, K. T., Cheng, J. C., \& Chan, C. M. (2020). Simulation Optimisation towards Energy Efficient Green Buildings: Current Status and Future Trends. Journal of Cleaner Production, 120012..

[25] Wang, Y., Wang, R., Li, G., \& Peng, C. (2020). An investigation of optimal window-to-wall ratio based on changes in building orientations for traditional dwellings. Solar Energy, 195, 64-81..

[26] M. V. B. P. \&. S. R. Turrin, " Design explorations of performance driven geometry in architectural design using parametric modeling and genetic algorithms " Advanced Engineering Informatics, vol. 25, no. 4, pp. 656-675., 2018.

[27] Abdullah, H. K., \& Alibaba, H. Z. (2020). Window Design of Naturally Ventilated Offices in the Mediterranean Climate in Terms of $\mathrm{CO} 2$ and Thermal Comfort Performance. Sustainability, 12(2), 473.. 